\title{
A IMPORTÂNCIA DO PROFESSOR RECUPERADOR NA ESCOLA PARA FAZER FACE A RETOMA DAS AULAS NO PERÍODO DE COVID-r9 EM MOCAMBIQUE (CASO DE ESTUDO MUNICÍPIO DE BOANE - BAIRRO CAMPOANE)
}

\author{
Manuel Pastor Francisco Conjo ${ }^{1}$ \\ Octavio Manuel de Jesus ${ }^{2}$ \\ Vitor Alves da Silveira ${ }^{3}$ \\ Daniel Bruno da Silva Triumpho ${ }^{4}$ \\ David Benjamim Chichango ${ }^{5}$ \\ Elisangela da Silva Evangelista ${ }^{6}$
}

RESUMO: O objetivo principal dessa pesquisa é mostrar a importância do professor recuperador em sala de aula trabalhando em parceria com o professor titular, como forma de apoiar no entendimento nas matérias no período pós paralisação das aulas e não só. $O$ professor recuperador e os novos mecanismos de apoio escolar serão fundamentais no processo de recuperação de alunos. Este estudo teve como metodologia o método qualitativo por ter sido considerado o mais adequado aos objetivos propostos, tendo sido utilizado como instrumento para coleta de dados o

I Bacharel e Licenciado em Ensino de Geografia pela Universidade Pedagógica de Maputo Moçambique. Técnico Superior em Higiene e Segurança no Trabalho e Meio Ambiente pela Ensine Moçambique. Mestrado em Gestão Ambiental pela Universidade Pedagógica de Maputo Moçambique. Doutorando em Ciência Florestal pela Universidade Federal de Viçosa - Minas Gerais Brasil. Instituição: Universidade Pedagógica de Maputo/Universidade Federal de Viçosa. E-mail: pastorconjooo7@gmail.com/m.conjo@hotmail.com.

2 Doutor em Ciências Pedagógicas, componente Educação Ambiental, através da disciplina de Geografia, no Instituto Central das Ciências Pedagógicas de Havana-Cuba. Mestrado em Didáctica da Geografia, Menção Geografia Económica e Social, no Instituto Superior Pedagógico "Enrique José Varona" em Havana-Cuba. Licenciatura em Ensino de História e Geografia, no Instituto Superior Pedagógico de Maputo-Moçambique. Funcionário do Ministério da Ciência, Tecnologia e Ensino Superior. Docente na Universidade Pedagógica de Maputo (desde 2006), categoria Professor Auxiliar, nas seguintes cadeiras científicas: Gestão Ambiental e Educação Ambiental; Didáctica de Geografia; Geografia de Moçambique I e II; Temas de Actualidade em Geografia Física Geral e Geografia Física Regional. Membro de Júri, Supervisor e Arguente nas Defesas de Monografias, Dissertações em Havana-Cuba e Maputo- Moçambique. Supervisor das teses de Doutoramento em Moçambique. Email: Octaviomzoor@yahoo.es.

3 Gestão Ambiental, Engenharia Agronômica, mestrado em Ciência Florestal. Doutorando em Ciências Ambientais e Florestais. Instituição: Universidade Federal de Viçosa.

4 Bacharel e licenciado em Geografia pela Universidade Federal de Viçosa. E-mail: danielbond2@gmail.com.

5 Concluinte do Curso Médio de Formação de Professores Primários (2005) pelo Instituto de Formação de Professores Primários de Chibututuine - Manhiça. Maputo. Licenciado em Ensino de Geografia com Habilitações em Turismo (2018), Universidade Pedagógica de Maputo. Professor de Geografia no Ensino Geral e Monitor nas disciplinas de Gestão e Educação Ambiental na Universidade Pedagógica de Maputo - Faculdade de Ciências da Terra e Ambiente. Mestrando em Gestão Ambiental, Universidade Pedagógica de Maputo.

6 Licenciada em Pedagogia com habilitação para Educação Infantil, Anos Iniciais do Ensino Fundamental, Gestão Escolar e Supervisão Pedagógica. Instituição: Universidade Federal de Viçosa. Email: elisaangela.evangelista@gmail.com. 
questionário e a observação. Acredita-se que a pesquisa seja relevante, uma vez que podemos perceber que a interferência de um professor recuperador em sala de aula, principalmente nas quais há um número excessivo de alunos, se faz imprescindível na contribuição da formação dessas crianças. Conclui-se que a presença do professor recuperador em sala de aulas seria mais valia na atualidade, principalmente quando se depara com salas que tem um número excessivo de alunos, como também nas salas cujo desenvolvimentos dos educandos são bem diferentes.

Palavras-chave: Educação, Professor recuperador, Recuperação dos Alunos.

ABSTRACT: The main objective of this research is to show the importance of the recovering teacher in the classroom working in partnership with the full professor as a way to support the understanding of the subjects after the class has stopped. The recovering teacher and the new school support mechanisms will be fundamental in the student recovery process. This study had as a methodology the qualitative method because it was considered the most adequate to the proposed objectives, and the questionnaire and observation were used as an instrument for data collection. It is believed that the research is relevant, since we can perceive that the interference of a recovering teacher in the classroom, especially in which there is an excessive number of students, is essential in the contribution of the training of these children. It is concluded that the presence of the recovering teacher in the classroom would be of added value, nowadays, especially when faced with rooms that have an excessive number of students, as well as in the rooms whose development of the students is quite different.

Keywords: Education, Recovering Teacher, Student Recovery.

\section{INTRODUÇÃO}

A educação moçambicana vem sendo marcada em alguns casos pelo fracasso escolar, pelo analfabetismo, evasão escolar e altos índices de repetência, o que têm gerado preocupação e discussão sobre o que fazer para garantir uma aprendizagem de qualidade. Esforços em várias áreas vêm sendo realizados no intuito de construir alternativas que venham provocar mudanças na escola e na prática pedagógica dos professores.

$\mathrm{Na}$ qualidade de educadores, sabe-se das dificuldades que se tem de atender de forma igualitária todos os educandos, e com qualidade, para que os objetivos e o desenvolvimento aconteçam, principalmente quando nos deparamos com uma sala com número excessivo de alunos, e na qual cada educando necessita de uma atenção especial e individualizada. Com isso, faz-se necessário a introdução de um professor recuperador, para que auxilie nesse processo de aprendizagem visando a atender às 
diversas características e ritmos de aprendizagem, a fim de melhorar o desempenho dos estudantes, sobretudo nos pós paralisação por conta da Covid I9.

O professor recuperador e os novos mecanismos de apoio escolar serão fundamentais no processo de recuperação de alunos com necessidade de reforço de aprendizagem, tendo em vista que este apoio é um importante meio de atender os alunos de maneira mais eficaz nas propostas de ensino aprendizagem, à medida que mais dúvidas podem ser esclarecidas e mais crianças ajudadas nas atividades. Desse modo, o professor regente terá mais condições de intervir de forma mais eficaz para melhorar o desenvolvimento dos seus alunos. Com a convivência no dia a dia a relação que se constitui entre professor recuperador e professor regente se solidifica, passando a ser fundamental para o pleno andamento das atividades.

Desta forma, considera-se a disponibilidade de um professor recuperador na escola, de modo que o aluno possa ter um momento de estudo extra turno ou mesmo no turno em que estuda. Isso deveria acontecer principalmente em salas de aulas com mais de 40 alunos, pois se depara com crianças na mesma serie que lê, e escreve muito bem, e aquelas que nem mesmo conhece o alfabeto.

A problematização inicial desta pesquisa se deu a partir de uma revisão bibliográfica associada a um conjunto de observações, experiências profissionais, conversas informais com objetivo de refletir sobre as dificuldades de se lecionar em uma sala com superlotação de alunos. Diante das exposições acima, nosso estudo busca mostrar a importância, de um "Professor Recuperador", na escola, principalmente no período pós paralisação das aulas por conta do Covid I9.

Do referido facto, surge como hipótese inicial que, o professor recuperador seria o mecanismo mais eficiente para sanar as dificuldades dos alunos nas salas de aula superlotadas, uma vez que estas estão sendo constituídas de alunos que se apresentam em níveis diversos de aprendizagem e desenvolvimento. Tornando assim um grande desafio, trabalhar com todos esses alunos no mesmo ambiente e ao mesmo tempo.

Dessa situação, surgiram algumas perguntas como: Qual seria a função do professor recuperador? $O$ professor deve retardar o tempo, para socorrer alguns alunos? Os planejamentos da turma devem ser diferenciados? Se sim em quais 
aspectos? Será que, apenas o professor regente consegue atender satisfatoriamente a todos?

Estas perguntas serão analisadas e discutidas com um objetivo de encontrar caminhos que levem ao sucesso do processo de recuperação dos alunos com dificuldades de aprendizagem; uma vez que, em determinadas situações deixa-se de desenvolver algum tipo de atividade em decorrência dessas diferenças de nivelamento. Então, a maior preocupação é oferecer em tempo hábil uma educação de qualidade que atenda aquelas crianças que estão além e aquém, ao mesmo tempo tanto no ensino primário completo quanto nas classes iniciais.

O presente estudo objetiva mostrar a importância, de um "Professor Recuperador" em sala de aula. Assim como também:

Encontrar uma solução eficiente para sanar mais facilmente as dificuldades dos alunos no período pós paralisação;

Expor a preocupação com aqueles alunos, os quais necessitam de ajuda diferenciada;

Mostrar a importância do professor recuperador em sala de aula, atuando diretamente com o professor regente.

Após inúmeras leituras e observações realizadas em algumas escolas, constatou-se que há um elevado número de alunos que apresentam dificuldade no processo de ensino-aprendizagem, ou seja, alunos com atraso escolar. Diante desse contexto educacional, faz-se necessário propor estratégias que solucionem tais problemas.

Nesse sentido, justifica-se a importância do referido trabalho, tendo em vista que este busca mostra a importância da atuação do professor recuperador em sala de aula, frisando que este se constitui numa oportunidade para que essas crianças resgatem sua autoestima e readquiram confiança em sua capacidade de aprender.

Para melhor delimitação da pesquisa, escolheu-se como metodologia uma pesquisa qualitativa por ter sido considerada a mais adequada aos objetivos propostos, tendo sido utilizado como instrumento para coleta de dados o questionário e a observação. O questionário é um dos procedimentos mais utilizados para obter informações, sendo uma técnica de grande confiabilidade, que pode ser utilizado para 
medir atitudes, opiniões, comportamentos, circunstancia da vida do cidadão, e outras questões.

Acredita-se que a pesquisa sege relevante, uma vez que podemos perceber que a interferência de um professor recuperador em sala de aula, principalmente nas quais há um número excessivo de alunos, se faz imprescindível para contribuir na formação dessas crianças, assim como contribuir de forma efetiva para a melhoria da qualidade da educação no período pós paralisação das aulas por causa do Covid e não só.

\section{Metodologia}

Utilizou-se para a realização deste estudo o método qualitativa por ter sido considerada a mais adequada aos objetivos propostos, tendo sido utilizado como instrumento para coleta de dados o questionário e a observação, definidos por Lakatos (2003, p. 20I), como sendo "um instrumento de coleta de dados, constituído por uma série ordenada de perguntas, que devem ser respondidas por escrito com e sem a presença do entrevistador".

Quanto à escolha dos questionários, optou-se por estes uma vez que, fazem o uso de material simples como lápis, papel e formulários, etc., e podem ser aplicados individualmente ou em grupo, por telefone e ou mesmo pelo correio, podendo incluir questões abertas, fechadas, de múltiplas escolhas, de respostas numéricas, ou apenas sim ou não (Minayo, 1999).

A pesquisa será realizada numa abordagem qualitativa, Campo da Pesquisa Social, que se apoia em dados sobre o mundo social, que são construídos nos processos de comunicação. Conforme Baver (2002), nesse tipo de pesquisa "estamos interessados na maneira como as pessoas espontaneamente se expressam e falam sobre o que é importantes para eles e como elas pensam sobre as suas ações e as dos outros". Entretanto, o uso complementar das técnicas pode enriquecer a coleta de dados e favorecer a interpretação dos resultados obtidos na pesquisa científica (Gil, 2002).

\section{I. População e Amostra}

De acordo com Oliveira (1999), a população é o conjunto de seres animados e inanimados que apresentam pelo menos uma característica em comum a ser estudada. 
E da população foi obtida uma amostra, onde conforme Marconi e Lakatos (1999, p.43), "é uma porção ou parcela do universo (população); e um subconjunto do universo".

Os sujeitos envolvidos nesse trabalho são todos diretamente ou indiretamente ligados a educação escolar. A população inicial da pesquisa são os professores de duas escolas primaria no bairro de Campoane, Município de Boane.

E para a amostra foram selecionadas vinte professoras com mais de dez anos de experiência profissional no campo educacional, que já lecionaram tanto em escola pública quanto em escola particular, com a faixa etária variando dos 28 aos 50 anos.

Para viabilizar nosso trabalho, foram aplicados questionários com esses professores, que se prontificaram a nos ajudar a obter as informações necessárias sobre as questões pesquisadas.

\subsection{Procedimentos e instrumentos de coleta de dados}

Nesta pesquisa, para a coleta dos dados foram utilizados questionários que foram aplicados em um grupo de professores, a fim de obter as informações que necessitávamos.

O questionário também chamado de Survey (pesquisa ampla) é um dos procedimentos mais utilizados para obter informações. É uma técnica de custo razoável, apresenta as mesmas questões, para todas as pessoas, garante o anonimato e pode conter questões para atender as finalidades especificas de uma pesquisa (Libâneo, I998).

Os questionários foram devidamente aplicados em 20 professoras, que prontamente responderam as 6 questões fechadas, assim como a questão aberta.

\section{Tabela. I Perguntas dos Questionário}

\begin{tabular}{|l|l|l|l|l|}
\hline Perguntas & $\begin{array}{l}\text { Resposta } \\
\text { A }\end{array}$ & $\begin{array}{l}\text { Resposta } \\
\text { B }\end{array}$ & $\begin{array}{l}\text { Respost } \\
\text { a C }\end{array}$ & $\begin{array}{l}\text { Respost } \\
\text { a D }\end{array}$ \\
\hline $\begin{array}{l}\text { Pergunta I: } \\
\text { Você leciona ou lecionou em: } \\
\text { ( ) Escola Pública } \\
\text { ( ) Escola Particular } \\
\begin{array}{l}\text { ( ) Ambas } \\
\text { ( ) Outras }\end{array}\end{array}$ & I2 & 4 & 4 & \\
\hline Pergunta 2: & & & & \\
\hline
\end{tabular}




\begin{tabular}{|c|c|c|c|c|}
\hline $\begin{array}{l}\text { Em quais dessas escolas você } \\
\text { diagnosticou maiores problemas de } \\
\text { aprendizagem? } \\
\text { () Escola Pública } \\
\text { () Escola Particular } \\
\text { () Ambas } \\
\text { () Outras }\end{array}$ & 20 & 0 & o & 0 \\
\hline $\begin{array}{l}\text { Pergunta 3: } \\
\text { Teve auxílio de um professor } \\
\text { recuperador? } \\
\text { ( ) Sim. } \\
\text { () Não } \\
\text { () As vezes }\end{array}$ & 8 & 12 & o & -...... \\
\hline $\begin{array}{l}\text { Pergunta 4: } \\
\text { Qual a importância do professor } \\
\text { recuperador em sala? } \\
\text { ( ) De suma importância } \\
\text { () Importante } \\
\text { () Irrelevante } \\
\text { ( ) Prefiro não responder }\end{array}$ & 20 & 0 & o & 0 \\
\hline $\begin{array}{l}\text { Pergunta 5: } \\
\text { Você enquanto professor titular } \\
\text { mantinha (mantem) contato com o } \\
\text { (s) professor (es) recuperador. } \\
\text { () Sim. Sempre } \\
\text { () Às vezes } \\
\text { () Nunca }\end{array}$ & 8 & 0 & 12 & -...... \\
\hline $\begin{array}{l}\text { Pergunta 6: } \\
\text { Você já atuou como professor } \\
\text { recuperador? } \\
\text { () Sim } \\
\text { ( ) Não }\end{array}$ & 8 & 12 & -........ & -...... \\
\hline
\end{tabular}

A sétima e última pergunta do questionário cuja resposta era de cunho pessoal se referia a opinião dos entrevistados sobre quais as principais dúvidas e (ou) dificuldade no que se referia a essa parceria entre professor titular e professor recuperador.

\section{Resultados e discussões}

Vinte questionários foram aplicados individualmente em vinte profissionais da educação via aplicativo de comunicação social WhatsApp. 
Este instrumento é composto por 7 perguntas. As duas primeiras têm como objetivo analisar quais escolas os entrevistados já lecionaram e em qual este diagnosticou maiores problemas de aprendizagem. A terceira e quarta pergunta buscam descobrir se estes já tiveram o auxílio de um professor recuperador e qual a importância que estes deram a este novo profissional em sala. A quinta e a sexta analisaram se estes professores mantinham um contato direto com o recuperador e se eles enquanto professores titulares já trabalharam como professor recuperador alguma vez em sua carreira como docente. A sétima e última buscou responder quais dificuldades e /ou dúvidas ocorrem nessa parceria entre professor titular e professor recuperador.

Outra fonte de pesquisa foi o material bibliográfico que tratou especificamente sobre o tema em questão.

Como pode ser visualizado na Tabela I, na primeira pergunta $60 \%$ dos entrevistados alegaram que trabalham somente em escola pública, contra $20 \%$ que trabalham em escola particular e outros $20 \%$ e ambas.

A pergunta 2 todos foram unânimes, ou seja, 100\% responderam que as maiores dificuldades de aprendizagem foram encontradas nas escolas públicas na quais eles trabalharam.

$\mathrm{Na}$ pergunta 3, 40\% dos entrevistados afirmaram ter tido auxílio de um professor recuperador e os outros $60 \%$ alegaram nunca ter tido este apoio.

Já na pergunta de número 4 , novamente todos foram unânimes em responder que o professor recuperador em sala de aula é de suma importância.

A pergunta 5 procurou saber se eles enquanto professores titulares e tendo o apoio de um professor recuperador mantinham um contato direto com ele, e como resposta podemos ver que $40 \%$ alegam que sim, que mantinham esse contato direto, deixando uma lacuna de 60\% de professores, que referem jamais ter mantido algum contato com um professor recuperador, por sinal todos das escolas públicas somente.

E finalizando as questões fechadas procuramos saber quais desses profissionais entrevistados já atuaram como professor recuperador e somente $40 \%$ responderam já ter atuado, os que trabalham também em escolas particulares, e 60\% nunca trabalharam como recuperador. Estas análises podem ser observadas de forma resumida na figura I, abaixo. 
Fig. I Análise gráfica dos resultados

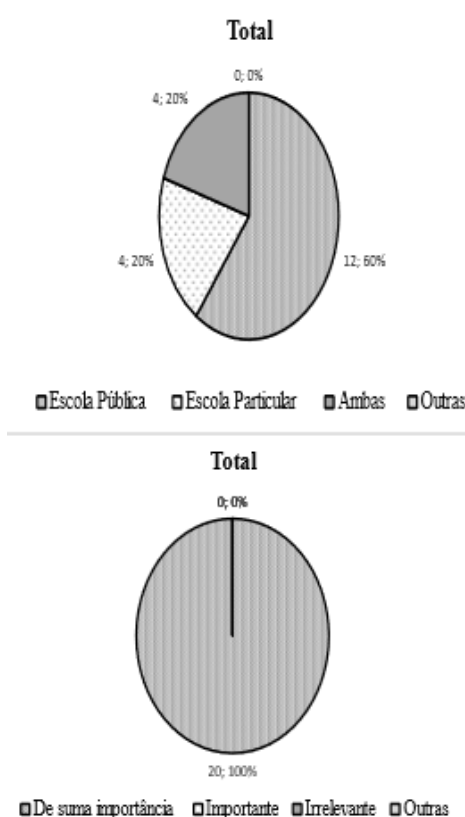

aDe suma importância GImportante QInelevarte QOutras

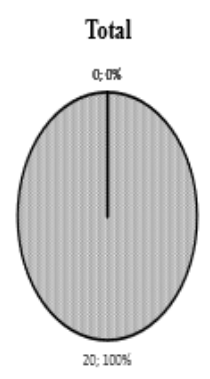

口Escola Pública aEscola Particular aAmbas aOutras

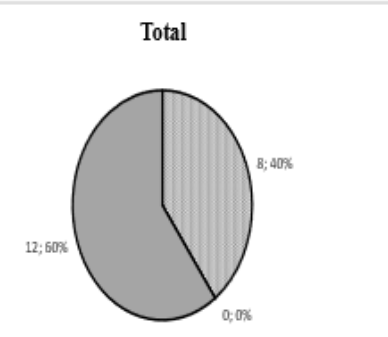

aSim aÁs vezes aNunca

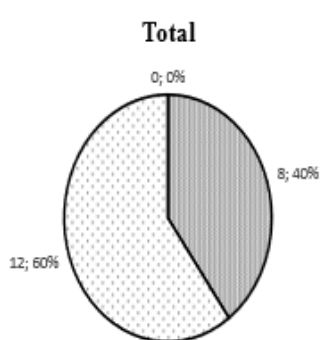

口Sim $\square$ Não $\square$ Ảs vezes

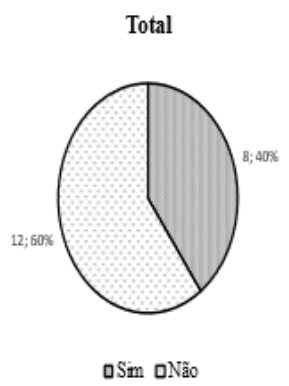

A sétima questão procurou diagnosticar quais são as maiores dificuldades ou dúvidas dessa parceria e de um modo geral percebemos que a maior dificuldade relatada pelos professores é que este profissional (professor recuperador) na maiorias das vezes ocupa duas funções (eventualidade $e$ recuperação), assim, este sempre é solicitado a fazer outras atividades e o reforço fica em segundo plano, ou seja, percebe-se que mesmo a escola tendo alunos com problemas de aprendizagem, necessitando de um recuperador para auxilia-los, as maiorias das escolas priorizam que este profissional seja utilizado em outras funções, deixando essa necessidade educacional em segundo plano.

Terminando esta analise, vale frisar que todos os entrevistados possuem ampla experiência profissional, já atuaram em escolas de relevo e alguns em escolas particulares, e todos foram unânimes em afirmar que o seu trabalho seria imensamente enriquecido se eles tivessem o apoio de um professor recuperador em sala.

Aos longos dos anos a função da escola vem se modificando, se adequando aos progressos e as necessidades da sociedade. A escola é vista como uma instituição de caráter fundamental para o desenvolvimento e crescimento cognitivo do ser humano. A escola ao traçar as suas metas, fazer projeções e elaborar suas propostas educacionais, deve propiciar aos seus alunos condições para desenvolver competências necessárias a 
aquisição dos processos da leitura e escrita com autonomia. Proporcionar condições que leve ao seu pleno desenvolvimento cognitivo (Nucci, 2009).

Culturalmente a função da escola e dos professores é ensinar, transmitir conhecimentos, pouco se preocupando a maneira como este processo se dará. De acordo com Moço (2012), não existe questionamento sobre a raiz da função da profissão docente que é ensinar, mas durante determinado tempo imaginou-se que identificando erros e punindo-os se chegaria à excelência educacional, tendo como base os sistemas avaliativos empregados. Testes e avaliação utilizados de formas quantitativas e promotoras, sendo utilizadas como parâmetros para ascensão a um novo nível no próximo ano, esquecendo-se muitas vezes da forma desigual como decorre o desenvolvimento destes alunos, o que torna imprescindível a presença de um professor recuperador para sanar tais desigualdades.

$\mathrm{Na}$ perspectiva de Barreto (2002), entende-se que, contudo, os resultados e o desempenho apresentado pelos alunos neste teste e avaliações devem ser tomados como referência para nortear os trabalhos a serem desenvolvidos pelos docentes com o intuito de que todas as crianças consigam com qualidade, autonomia e aprendizagem acompanhar e assimilar os conteúdos curriculares e efetivar a aprendizagem. Considerando que a paralisação da qual se esteve inserido implica a frequência de dois anos letivos num só ano civil.

Depois da paralisação e na eminência das crianças terem que voltado as aulas e com uma passagem automática para as classes sem exame, e a ter que rever a matéria da classe anterior quase que não feita, é imprescindível para que todas as crianças possam se apropriar e se desenvolver plenamente nos aspectos cognitivos, afetivos, sociais e motores várias competências e habilidade que devem ser trabalhadas e desenvolvidas, respeitando as particularidades de cada um, levando em conta os fatores externos e internos, mas dependendo esforços para facilitar o aprendizado. Quebrando paradigmas e estando aberto a novas propostas como é o caso da do professor recuperador (Nucci, 2009).

Toda equipe deve estar atenta e com um olhar crítico para que no momento em que perceber que algum aluno não está apresentando os mesmos desempenhos que a maioria ou o que é esperado para a sua idade ou etapa que está inserida, deve-se iniciar uma sondagem para detectar qual a dificuldade de aprendizagem ele apresenta, 
traçando estratégias e metas em busca de soluções viáveis e objetivas. $\mathrm{Na}$ inclusão e implementação da recuperação ou reforço escolar nas unidades escolares deve-se pensar que tipo será adotado, quais as estratégias serão tomadas, que profissionais farão parte e contribuirão para que o processo se desenvolva plenamente (Pereira, 2013)

Observado o défice de aprendizagem em alguns, deve-se proporcionar aos alunos a recuperação contínua, cujo responsável deve ser o professor regente. Introduzida no cotidiano escolar, a recuperação contínua deve proporcionar aos alunos através de atividades diversificadas e referentes as dificuldades apresentadas pelos alunos uma reorientação de estudo, levando em conta o ritmo e particularidade das dificuldades de cada aluno utilizando-se de diversas estratégias e o atendimento individualizado (Nucci, 2009).

Outra forma das escolas promover o reforço e a recuperação escolar é oferecêla de forma paralela, ocorrendo em período diverso ao das aulas regulares, com um profissional que possua um perfil adequado e que possa proporcionar atividades que surtam efeito nas aprendizagens dos alunos (Barreto, 2002). Deste modo, a recuperação paralela e o reforço escolar, principalmente nesta fase da pandemia, devem ser planejados cuidadosamente, avaliando resultados, dificuldades e a escolha do profissional de foram a proporcionar o sucesso escolar como nos orienta (Nucci, 2009).

No entanto para que a recuperação e o reforço escolar possam garantir que as dificuldades sejam realmente superadas devem ser proporcionado as escolas tempo para discutir e planejar estratégias, destinação de espaço pedagógico adequado, avaliação diagnóstica da recuperação paralela, correção de trajetórias, análise e discussão de resultados (Barreto, 2002).

Portanto, para que nos processos de reforço e recuperação escolar se obtenha ganhos, é preciso que todos os atores envolvidos com o processo educacional acreditem e colaborem dentro de suas obrigações, para que juntos se atinja o sucesso escolar. Professor ou escola não conseguirá nada trabalhando isoladamente e sem um planejamento conciso, objetivo e dinâmico. Recuperar um aluno é ardiloso, mas com o apoio e parcerias adequadas, será possível obter sucesso (Pereira, 2013). 


\section{Conclusão}

Este trabalho se propôs investigar a importância do professor recuperador em sala de aula principalmente no período pós paralisação das aulas, visando mostrar que a educação escolar é um desafio para qualquer educador, independente da instituição de ensino, sobretudo neste momento em que experimentamos a pandemia do Covid I9, seus aspectos e impactos decorrentes.

A pesquisa de campo, assim como a revisão bibliográfica, veio para confirmar que a recuperação de alunos com dificuldade em assimilar os conteúdos é um problema comum entre os educadores, e que um professor recuperador faz muita diferença quando caminha junto com o professor regente.

Com a aplicação dos questionários, constatou-se a preocupação de se ter um professor recuperador que auxilie para equilibrar o desenvolvimento dos alunos nos pós paralisação na maioria das escolas, deixando clara a importância desse profissional na educação, trabalhando lado a lado com o professor titular, visando o pleno desenvolvimento no aprendizado.

A partir da análise dos dados coletados pudemos perceber que todos os professores entrevistados possuem uma formação acadêmica adequada, assim como, também ampla experiência profissional, mesmo assim todos são unânimes em dizer que o apoio de um professor recuperador é de suma importância no trabalho pedagógico, principalmente quando este se depara com uma sala de aula superlotada, com alunos apresentando dificuldades de aprendizagens.

Nesta fase de retoma das aulas, aonde o desenvolvimento dos alunos foi bastante afetado, torna-se de suma impotência introdução de professor recuperador para limar as dificuldades dos alunos com défice de entendimento da matéria, principalmente em turmas numerosas.

\section{Referências}

ALMEIDA, M. I, Formação contínua de professores: Múltiplas possibilidades inúmeros parceiros. Evandro Ghedim. (org). Perspectivas em formação de professores, manaus -am: editora valer, 2007, v.I, p.I25, I3I.

ANTUNES, C. Novas maneiras de ensinar. SP, Artemed, 2002. 
ANTUNES, celso. trabalhando habilidades: Construindo idéias. SP, Scipione, zoor. ARAÚJO, Osmar Ribeiro, Modos de leitura de alfabetizadoras. história, memória e representação, 2005. 218f dissertação (mestrado em educação) faculdade de educação, Universidade Federal de Uberlândia, 2005.

BARRETO, Elba Siqueira de Sá. Os desafios da avaliação nos ciclos de aprendizagem. Disponível em http://www.crmariocovas.sp.gov.br/pdf/pro/o7_desafios_da_avaliacao.pdf Acesso em 20/02/2021.

LIBÂNEO, José. C. Pedagogia e padagogos, para quê? SP: cortez, 1998. p.23-63.

MOÇO, Anderson. Vencendo os erros. Disponível em http://revistaescola.abril.com.br/gestao-escolar/vencendo-erros-67856r.shtml Acesso em $20 / 02 / 2021$.

NASCIMENTO, Cláudia Terrado; FREITAS, Soraia Napoleão. Possibilidades de atenção á aprendizagem infantil em contexto hospitalar. in: Matos, Elizete Lúcia Moreira; Torres, Patrícia Lupion (orgs). Teoria e prática na pedagogia hospitalar: novos cenários, novos desafios. Curitiba: Champagnat, 2010. p 21-40.

NÓVOA, antônio. formação de professores e profissão docente. in nóvoa antônio (coord). os professores e sua formação. zed. lisboa, dom quixote, 1997.

NUCCI, Nereida Maria. Recuperação - oportunidade de sucesso. Disponível em http://www.webartigos.com/artigos/recuperacao-oportunidade-desucesso/15680/ Acesso em 20/02/2021.

PEREIRA, Elaine de Castro Rocha Andrade. Reforço e recuperação escolar: uma oportunidade de efetivação do ensino. 2013.

DOS SANTOS, Sonia Maria. Histórias de alfabetizadoras brasileiras -entre saberes e práticas 200I, 335f. tese (doutorado em educação), Pontifíca Universal Católica de SP, 2001.

STAKER, R. Estudo de caso em pesquisa e avaliação educacional. Educação e seleção. SP, Fundação Carlos Chags, n7, jan/jun.1983. Faculdade de Educação, Universidade Federal de Uberlandia, 2005, 
WOLCOTT. H. W. Criteria for ethnographic approach to reserarch in education. human organization, 34:11I-128, 1975.

ZACARIAS, Vera Lúcia Camara F. O que são realmente dificuldades de aprendizagem? disponível

em:

http//www.centrorefeducacional.com.br/adificieis.htm. acesso em 2I de marco 2020. 